\title{
RECURSOS TURÍSTICOS Y PATRIMONIO FERROVIARIO. EL CASO DEL FERROCARRIL TRASANDINO CHILENO. IDENTIFICACIÓN, CARACTERIZACIÓN Y EVALUACIÓN
}

\author{
Cristian Urzúa Aburto \\ Investigador Área Patrimonio Histórico-Cultural \\ Centro de Investigación Turismo y Patrimonio \\ cristianurzua@cityp.org
}

\section{RESUMEN}

En la presente investigación se busca analizar los usos y los recursos turísticos en torno al antiguo Ferrocarril Trasandino Los Andes-Mendoza, en su vertiente chilena. En base a un análisis cualitativo integral a través de prospecciones en terreno, entrevistas e investigación bibliográfica y documental, se reconocen sus recursos turísticos reales y potenciales que permiten evaluar y explorar las distintas posibilidades de uso del patrimonio ferroviario. Como hipótesis se establece que si bien existe un uso turístico del ferrocarril, este se encuentra subutilizado en relación a la formidable infraestructura material y riqueza de las expresiones culturales que perviven en Los Andes. Al final se realiza una propuesta de productos turísticos susceptibles de ser desarrollados.

Palabras claves: Recurso turístico, potencial turístico, turismo ferroviario, patrimonio industrial, Ferrocarril Trasandino Chileno. 


\title{
TOURISM RESOURCES AND RAILWAY HERITAGE. THE CASE OF THE CHILEAN TRASANDINO RAILROAD. IDENTIFICATION, CHARACTERIZATION AND EVALUATION
}

\author{
Cristian Urzúa Aburto \\ Investigador Área Patrimonio Histórico-Cultural \\ Centro de Investigación Turismo y Patrimonio \\ cristianurzua@cityp.org
}

\begin{abstract}
This research aims to analyze the tourist uses and resources of the former Trasandino Los Andes-Mendoza Railway in its Chilean side. Based on a qualitative approach and through field surveys, interviews and bibliographical and documentary research, the results identify the real and potential tourist resources of the train and allow the research to evaluate and explore the different possibilities of use of the rail heritage. The conclusions highlight that the rail has been used for tourism purposes. In spite of this and its formidable material infrastructure and richness of its cultural expressions, its potential has not been capture yet. Based on this, this article makes a proposal of tourist products to be developed.
\end{abstract}

Key words: Tourism resource, tourist potential, railway tourist, industrial heritage, Chilean Trasandino Railway. 


\section{INTRODUCCIÓN}

Desde mediados del siglo XIX hasta últimas décadas del siglo XX, el ferrocarril constituyó el principal medio de transporte en Chile. Su irrupción cambió la fisonomía urbana-rural, agilizando el transporte de carga y pasajeros, creando asimismo una identidad en torno a sus trabajadores y usuarios. El tren prácticamente conectó todo el país, hasta que finalmente fue reemplazado por nuevas formas de transporte, momento cuando se comienza a desmantelar su infraestructura. Pese a ello, en el último tiempo, Empresa de Ferrocarriles del Estado (EFE) junto a distintas instituciones, ha comenzado a rehabilitar antiguos trenes para ponerlos al servicio del turismo, de acuerdo a una tendencia mundial que ha visto los beneficios económicos, sociales y culturales que el turismo ferroviario produce sobre los territorios, contribuyendo al desarrollo local y el cuidado del patrimonio ferroviario.

Para los proyectos que pretendan evaluar el potencial del patrimonio ferroviario para su habilitación turística y/o patrimonial, es necesario una investigación cualitativa sistémica que permita ponderar de manera adecuada el bagaje cultural en toda su integridad, de acuerdo al contexto histórico, territorial, económico y sociocultural. Con ello, se podrán tomar decisiones informadas en la jerarquización de los recursos, necesidades de conservación y proyección turística del patrimonio ferroviario. Cualquier iniciativa desarrollada al respecto, en todo caso, debe ser implementada de manera sustentable, de manera que enriquezca a la cultural local, sea amigable con el medio ambiente y distribuya la riqueza a todos los sectores involucrados.

En este escenario, este estudio busca identificar, caracterizar y evaluar los recursos patrimoniales asociados al Ferrocarril Trasandino Los Andes-Mendoza, por el lado chileno. Se reconocen recursos reales como el Tour de la Góndola Carril, como el producto más elaborado de la zona, y a la ex Estación del Ferrocarril como un lugar emergente que sirve de centro cultural, información e investigación turística. Se identifican además recursos potenciales susceptibles para el desarrollo de actividades turísticas y/o patrimoniales como la Maestranza de Ferrocarriles de Los Andes, el campamento ferroviario de Salto del Soldado, la Estación de Río Blanco y los vestigios de la antigua Estación Hermanos Clark.

Para satisfacer los objetivos planteados se realizaron prospecciones en terreno, entrevistas, observación participante e investigación documental y bibliográfica. La información recabada de los recursos ferroviarios fue sistematizada y evaluada a partir de la clasificación desarrollada por Camara y Morcate (2014) y expresados a través de una matriz FODA. Por último se hace una propuesta de portafolio de productos turísticos 
de dicho patrimonio ferroviario. Se establece como hipótesis que si bien se han desarrollado ciertos productos turísticos en torno al Ferrocarril Trasandino Chileno, gran parte de su patrimonio material e inmaterial se encuentra desaprovechado.

El estudio del ferrocarril en Chile ha tenido un desarrollo versátil de acuerdo a la disciplina que lo estudia y los objetivos de su investigación. Se han desarrollado estudios generales en torno a la historia del ferrocarril en Chile (Alliende, 1993; Thomson y Angerstein, 2000; Moraga, 2013 y 2015b), desde el punto de vista del patrimonio cultural (Rojas y Romero, 2006; Rojas, Carvajal y Ortega, 2015) y como producto turístico (Thomson, 2007 y 2003; Casals y Errázuriz, 2013). Debemos consignar también una enorme cantidad de estudios locales sobre estaciones, ramales y trabajadores que no citamos por numerosas. Específicamente, el caso del Ferrocarril Transandino ha sido estudiado desde distintos puntos vista (Thomson y Argenstein, 2000; Thompson 2005; Seisdedos, 2009; Lacoste, 2013; Moraga, 2015a). Este conjunto de investigaciones demuestra la importancia histórica y valor patrimonial del ferrocarril, y que sirven de referencia para la evaluación de sus instalaciones.

Si bien hay antecedentes de evaluación de recursos turísticos en la Provincia de Los Andes con la identificación de sus recursos a partir de la precepción de profesionales, turistas y lugareños (Negrete, 1987) y la creación de un plan de ordenamiento y promoción turística para el destino Valle de Aconcagua (Aconcagua Turismo 2020, 2013), estos otorgan una mirada general que toca sólo de manera tangencial o incompleta al patrimonio ferroviario. Por ello, lo que se busca demostrar aquí es que podemos entender el patrimonio ferroviario como un conjunto singular, interrelacionado y contextualizado con su entorno, aspectos analíticos que enriquecen su conocimiento y las posibilidades de turistificación, que pueden ir desde aspectos no invasivos como su inclusión en una ruta patrimonial hasta su abierta intervención para la musealización de estaciones.

Ante un escenario donde en Chile la Estrategia Nacional de Turismo 2012-2020 tiene un correlato regional (Plan de Turismo de la Región de Valparaíso) y otro interprovincial (Aconcagua Turismo 2020), se hace pues necesario reducir la escala de observación e indagar sobre aquellos elementos que pueden ser potencialmente importantes para el turismo. La V Región de Valparaíso se ha convertido en una zona líder en el desarrollo turístico, pero internamente este avance ha sido desigual en el territorio pues se concentra principalmente en los balnearios litorales, no así en sus valles interiores y el sector cordillerano. Por lo anterior, es necesario estudiar sus recursos para diseñar las estrategias que permitan el desarrollo turístico de la región en su conjunto. 


\section{METODOLOGÍA}

Este estudio busca identificar, caracterizar y evaluar el patrimonio ferroviario para su puesta en valor para el turismo, proceso que se desarrollará a partir de la recopilación y análisis de la siguiente información:

- Recopilación de información a través de fuentes bibliográficas y documentales.

- Trabajo de campo consistente en prospección territorial de sitios, estaciones ferroviarias e instalaciones relacionadas.

- Observación participante Día del Patrimonio Cultural 2015 y 2016, Tour góndola carril y otras actividades relacionadas al tren.

- $\quad$ Entrevistas a actores vinculados al ferrocarril y ex ferroviarios.

Para la sistematización de los recursos turísticos seguiremos el modelo de Camara y Morcate (2014) que se expresa en la Tabla $n^{\circ} 1$, a partir de cuyo criterio seleccionaremos los hitos patrimoniales más relevantes del Ferrocarril Trasandino Chileno para su evaluación turística.

\section{Tabla $n^{0}$ 1: Clasificación de los Recursos Territoriales Turísticos}

\begin{tabular}{|c|c|c|}
\hline Clasificaciones & Categorizaciones & Componentes \\
\hline \multirow[b]{2}{*}{ Básicos } & Naturales & 1. Atractivos o recurso natural y paisajístico \\
\hline & Culturales & $\begin{array}{l}\text { 2. Recursos históricos-monumental, técnicos, etnológicos y } \\
\text { artisticos } \\
\text { 3. Recursos artesanales y gastronómicos } \\
\text { 4. Folklore, fiestas } \\
\text { 5. Acontecimientos programados }\end{array}$ \\
\hline \multirow{3}{*}{ Complementarios } & La Planta turística & $\begin{array}{l}\text { 1. Equipamiento turistico (Alojamiento, Alimentación, } \\
\text { Esparcimiento y otros servicios) } \\
\text { 2. Instalaciones (de agua y playa, de montaña, generales) }\end{array}$ \\
\hline & Las infraestructuras & $\begin{array}{l}\text { 1. Transporte } \\
\text { 2. Comunicaciones } \\
\text { 3. Sanidad } \\
\text { 4. Energia } \\
\text { 5. Salud }\end{array}$ \\
\hline & La superestructura turistica & $\begin{array}{l}\text { 1. Actores del sector turistico (Estatales, privados, comunidad } \\
\text { local) } \\
\text { 2. Procesos y gestión turistica (Áreas politicas, económicas, } \\
\text { sociales, culturales, ecológicas, de gestión y planeación y de } \\
\text { tecnologia e innovación) }\end{array}$ \\
\hline
\end{tabular}

Fuente: Camara y Morcate (2014). 
El modelo propuesto divide los recursos turísticos, tanto reales como potenciales, entre Básicos y Complementarios. Entre los primeros el autor propone una división en dos categorías: Recursos Naturales y Recursos Culturales que se basan en el modelo de OEA (1978) y OMT (1978). En cuanto a los Recursos Complementarios, el sistema de Planta Turística se basa en Boullón (2006), al igual que el de las Infraestructuras, salvo en su punto 5 (Salud), integrado por los autores. Junto a ello se agrega la categoría de superestructura turística de Boullón (2006) y Almeida (2009), más el componente Actores del sector turístico, concebida por los autores, y los Procesos de gestión turística según el modelo de SECTUR (2005) y el mismo Almeida (2009). Las ventajas de este modelo es que contempla todos los aspectos que intervienen en la evaluación de los recursos, con una mirada integral y un análisis que privilegia lo cualitativo.

El conjunto de la información se sistematizará en una matriz FODA, identificando fortalezas, oportunidades, debilidades y amenazas en la intervención turística del ferrocarril. Al final se propone un portafolio de productos turísticos idóneos para ser desarrollados por agentes del sector.

\section{ELFERROCARRIL TRASANDINOY SU VALOR HISTÓRICO-PATRIMONIAL}

El ferrocarril se instala en Chile desde mediados del siglo XIX para el trasporte de recursos para la emergente industria minera. En 1851 se funda en Chile el ferrocarril de Caldera a Copiapó para la conducción de plata y cobre desde los asientos mineros hasta la costa, reemplazando el antiguo sistema de transporte de carretas y mulas. Pronto el Estado nota que está nueva tecnología trae enormes ventajas a la economía y a la conectividad territorial. En 1863 se inaugura la línea ferrea que une la ciudad de Santiago a la de Valparaíso y luego se construye la línea longitudinal al norte y al sur, uniendo a Chile de Arica hasta Puerto Montt y desde la cordillera a la costa a través de sus ramales. En consecuencia, el ferrocarril se convierte en el principal medio de transporte de carga y pasajeros convirtiéndose en un agente catalizador de la economía chilena.

En tal contexto, los hermanos Juan y Mateo Clark fueron los encargados de construir un ferrocarril internacional que dinamizará las relaciones comerciales entre Chile y Argentina. Tan audaz hazaña suponía una gestión extraordinaria para conseguir créditos e inversionistas, además de vencer todos los obstáculos técnicos de la construcción en altura. Previamente la Sociedad Clark y Cía. había construido el telégrafo que unía Valparaíso y Santiago con Buenos Aires en 1872 y con esa experiencia idearon la construcción de un tren que uniera a las ciudades de Los Andes y Mendoza. La construcción del Ferrocarril Trasandino en Chile aunque fue autorizada en 1872, tuvo varias interrupciones que postergaron su inauguración hasta el 5 de abril de 1910, con la apertura del túnel Las Cuevas. Los factores climáticos y las fuertes pendientes obligaron 
a adquirir piezas de gran calidad y tecnología de punta, especialmente acondicionada para el clima de montaña (Thomson y Argenstein, 2000: pp. 148-155).

La historia del trasandino es una historia de altos y bajos, marcada por su baja rentabilidad, el acondicionamiento a nuevas fuentes energéticas y al inclemente clima de montaña. En 1927 se inaugura la electrificación entre Juncal y Las Cuevas, en Argentina y en Chile. Hacia 1950 se electrificó todo el tramo chileno desde Juncal a Los Andes, lo que llevó a la incorporación de maquinaria eléctrica para los trenes y la construcción de subestaciones. La inauguración de una nueva estación en los Andes en 1954 marca la etapa de electrificación total del trasandino por el lado chileno. En 1934 el aluvión de Cacheuta en el lado argentino causó graves daños en las instalaciones del ferrocarril, destruyendo cien kilómetros de vía y dejándolo fuera de servicio hasta 1944. En 1950 se integran las locomotoras diésel que remplazan definitivamente al sistema eléctrico en 1969. En la década de 1970 con la finalización de las obras de pavimentación del camino internacional, el tráfico de pasajeros experimentó una fuerte caída hasta suspenderse en 1879. El transporte de carga continuó durante algunos años, hasta suspenderse el servicio en julio de 1984 debido a un alud que destruyó la línea por el lado chileno. Actualmente la vía del ferrocarril es usada como servicio de carga de cobre para la División Andina de Codelco Chile. Entonces se retira la electrificación de la vía, operando solo la tracción diésel, y el túnel internacional se habilita para el tráfico de camiones con cargas peligrosas (Lacoste, 2013: p. 32; CMN, 2005)

El valor de Ferrocarril Trasandino radica en ser una magna y prolija obra de ingeniería que en su época representó los más altos estándares tecnológicos, necesarios para superar el enorme obstáculo que representó la cordillera de Los Andes. Estas piezas "constituyen un testimonio excepcional del Ferrocarril Trasandino, gran obra de ingeniería que, superando como obstáculo geográfico tan formidable como la Cordillera de los Andes, facilitó la integración entre Chile y Argentina durante buena parte del siglo XX" (CMN, 2005). Su construcción se equipara a las grandes obras de ingeniería de su época como el Canal del Panamá o el Canal de Suez.

\section{RECURSOS TURÍSTICOS DEL FERROCARRIL TRASANDINO}

El Ferrocarril Trasandino Chileno guarda una infraestructura extraordinaria que da cuenta de la magnitud material, humana y operacional del ferrocarril durante su vida útil. De acuerdo a Seisdedos (2009) las obras de la sección chilena constan de "aproximadamente 4,2 km de muros de contención; $270.000 \mathrm{~m} 3$ de tierras desplazadas y 6.000 ton de acero utilizadas en la construcción de la vía. La construcción de 23 puentes para un total de 364,7 metros lineales; $6 \mathrm{~km}$ de túneles y cobertizos; 8 asentamientos ferroviarios: 3 estaciones, 3 paraderos y 2 campamentos para un total de $25.000 \mathrm{~m} 2 \mathrm{de}$ 
construcciones en más de 24 ha de uso ferroviario exclusivo" (p. 54). Pese a que una

parte de este material ha desaparecido, queda todavía una importante infraestructura, la mayor parte vinculada a sus ex estaciones. A partir de ello se han identificando varias zonas de importancia histórica-patrimonial con potencial para el desarrollo turístico que hemos sistematizado y calificado en la tabla $\mathrm{n}^{\circ} 2$ :

\section{Tabla no 2: Uso y Potencial de los Recursos Turístico del Ferrocarril Trasandino Chileno}

\begin{tabular}{|c|c|c|c|c|c|}
\hline Recurso & Tipo & Uso actual & $\begin{array}{l}\text { Uso } \\
\text { Potencial }\end{array}$ & $\begin{array}{l}\text { Valor } \\
\text { actual }\end{array}$ & $\begin{array}{l}\text { Valor } \\
\text { Potencial }\end{array}$ \\
\hline $\begin{array}{l}\text { Ex Estación de Ferrocarriles } \\
\text { de Los Andes }\end{array}$ & Real & $\begin{array}{l}\text { Centro cultural, } \\
\text { investigación y } \\
\text { difusión turística, hito } \\
\text { de ruta }\end{array}$ & $\begin{array}{l}\text { Museo, habilitación } \\
\text { depedencias anexas }\end{array}$ & $3.6^{*}$ & $5 *$ \\
\hline Tour Góndola Carril & Real & Tour en operación & $\begin{array}{l}\text { Habilitación de } \\
\text { nuevos coches y } \\
\text { máquinas }\end{array}$ & 3.8 & 4.7 \\
\hline $\begin{array}{l}\text { Maestranza Ferroviaria de Los } \\
\text { Andes }\end{array}$ & Potencial & $\begin{array}{l}\text { Uso industrial, } \\
\text { apertura esporádica a } \\
\text { la comunidad. }\end{array}$ & $\begin{array}{l}\text { Museo, sitio de } \\
\text { interpretación, hito } \\
\text { de ruta }\end{array}$ & 3.3 & 4.7 \\
\hline Parada de Vilcuya & Potencial & Parada ocasional tour & Sitio de intepretación & 1.6 & 2.3 \\
\hline $\begin{array}{l}\text { Campamento ferroviario de } \\
\text { Salto del Soldado }\end{array}$ & Potencial & $\begin{array}{l}\text { Mirador ocasional, } \\
\text { Estacionamiento de } \\
\text { vehículos }\end{array}$ & $\begin{array}{l}\text { Mirador estructurado, } \\
\text { circuito de trekking, } \\
\text { hito de ruta }\end{array}$ & 2.4 & 4.1 \\
\hline Estaciỏn de Rio Blanco & Potencial & $\begin{array}{l}\text { Parada de tour, visitas } \\
\text { ocasionales, uso } \\
\text { Minera Codelco } \\
\text { Andina }\end{array}$ & $\begin{array}{l}\text { Museo, sitio de } \\
\text { interpretación, hito } \\
\text { de ruta }\end{array}$ & 2.8 & 4.1 \\
\hline Estación Hermanos Clark & Potencial & Abandonada & $\begin{array}{l}\text { Museo de sitio, } \\
\text { mirador, circuito de } \\
\text { trekking, hito de ruta }\end{array}$ & 2.1 & 3.2 \\
\hline $\begin{array}{l}\text { Día del Trabajador } \\
\text { Ferroviario }\end{array}$ & Potencial & Celebración Privada & Celebración Pública & 3.3 & 4.6 \\
\hline
\end{tabular}

Fuente: Elaboración propia en base a Camara y Morcate (2014). *Calificación de uso y potencial de recursos turísticos donde: 1: Bajo; 2: Medio-Bajo; 3: Medio; 4: Medio-Alto; 5: Alto.

De acuerdo a esta sistematización de la información, hemos identificado 2 zonas de recursos reales que pueden fortalecer y diversificar su oferta, 4 zonas con potencial de desarrollo turístico (dejando fuera a la parada de Vilcuya) y una expresión inmaterial en el Día del Trabajador Ferroviario. A continuación presentamos un análisis de seis zonas con potencialidad turística: 1) Ex estación del Ferrocarril Trasandino de Los Andes; 2) Tour Góndola Carril a Río Blanco; 3) Maestranza Ferroviaria de Los Andes; 4) Campamento ferroviario El Salto del Soldado; 5) Estación de Ferrocarriles de Río Blanco; y 6) Estación de Ferrocarriles Hermanos Clark. 


\section{Ex Estación del Ferrocarril Trasandino de Los Andes}

En la actualidad, no obstante haber cesado el traslado de pasajeros, las dependencias de la Ex Estación del Ferrocarril Trasandino de Los Andes constituye un referente urbano con un alto valor patrimonial derivado de su historia, arquitectura y el arte de su mural "El abrazo de los pueblos" del muralista Gregorio De la Fuente, que representa las relaciones históricas entre Argentina y Chile. La estación fue construida en 1954 convirtiéndose un nodo que articuló las combinaciones entre el ferrocarril de Santiago-Valparaíso a través de la estación de Llay-Llay y su ramal hacia Los Andes, lugar donde confluían una gran cantidad de pasajeros y trabajadores, transformándose en un nodo del desarrollo local.

Desde el cese de los viajes en 1993, la estación entra en un proceso de deterioro físico y programático de sus espacios. Desde mediados del 2000 el edificio lo ocupan distintas instituciones, pero en 2009 se abandona definitivamente, entrando en un periodo de deterioro mucho más agudo con depósitos de basura, pernoctación de indigentes, robo de vigas, pequeñas quemas, rompimiento de vidrios y rayado de muros. Frente a esta amenaza, la ciudadanía se moviliza con el objetivo de promover la recuperación del edificio.

En este escenario, Codelco División Andina, con la adjudicación de un Fondo de Inversión Social (FIS) obtiene recursos para la recuperación del inmueble, junto al aporte de Pro Aconcagua y otras entidades, restaurando el hall del edificio junto al mural. Una segunda etapa busca rehabilitar el ala oeste del edificio construyendo un espacio para conferencias y conciertos. La última fase contempla recuperar todo su frontis, una alameda empedrada con un monolito dedicado a los hermanos Clark.

El edificio acoge hoy a la Fundación Orquesta Sinfónica Infantil de Los Andes (FOSILA), a la Corporación de Desarrollo Pro Aconcagua y el Centro de Investigación Turismo y Patrimonio (CITYP). Al alero de estas instituciones funciona como centro de actividades socioculturales y promoción e investigación turística del destino Valle de Aconcagua y la V Región de Valparaíso. La estación cuenta con instalaciones adecuadas para visita: posee baños, infografías y folletería. Como el edificio se encuentra en el perímetro urbano está cercano a servicios de alojamiento, alimentación y esparcimiento, así como transporte permanente de taxis, colectivos y buses. 


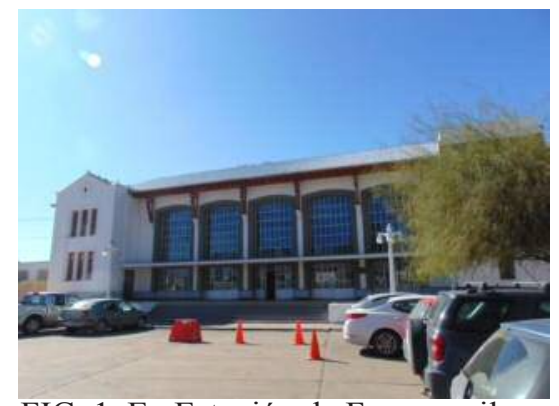

FIG. 1: Ex Estación de Ferrocarriles de Los Andes

$\mathrm{S}$

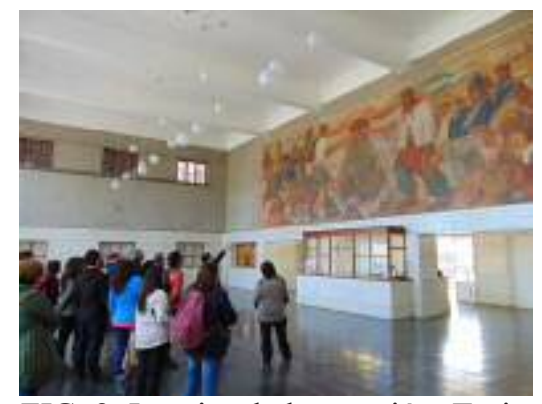

FIG. 2: Interior de la estación. Turistas visitando el mural "El abrazo de los pueblos"

\section{Tour Góndola Carril a Río Blanco}

La góndola carril T-1024 de 1926 es un pequeño bus adaptado para uso ferroviario que data de 1926, es el único exponente de su tipo en el país, por lo que fue declarado Monumento Nacional el 20 de enero de 1998. Este tren turístico es operado por la Asociación Chilena de Conservación del Patrimonio Ferroviario (ACCPF), una sociedad sin fin de lucro que ha trabajado en la restauración de esta y otras piezas del trasandino. Originalmente fue un vehículo de calle que atendía entre Coquimbo y La Serena para luego ser reconvertido al sistema de ruedas ferroviarias. Esta máquina "Fue traspasada al Ferrocarril Trasandino cuando llegó la segunda partida de locomotoras Dt-4,100 en la década de 1950, que reemplazó su servicio a Rivadavia por este tipo de locomotoras, más dos coches Greg. El servicio de Góndolas se hizo fuerte en los años cincuenta cuando incluso realizaban viajes entre Los Andes (Chile) y Mendoza (Argentina). Fueron desplazadas con la llegada de los automotores Schindler al Trasandino, con lo cual empezaron a desaparecer de circulación, salvo la t-1024, que permaneció para servicio interno hasta el cierre del servicio internacional" (Casals y Errázuriz, 2013: pp. 95-96).

En el 2006, para el Día del Patrimonio Cultural, el municipio de Los Andes y la ACCPF habilitan la Góndola Carril como un producto turístico desarrollando un viaje por el corredor que se extiende desde la maestranza de Los Andes hasta la localidad de Río Blanco, siguiendo el trazado cordillerano del ex trasandino. El tour se realiza el primer domingo de cada mes, desde marzo a noviembre. La capacidad de la góndola es de 28 pasajeros con un promedio por viaje de 24 turistas, lo que da una cifra de 216 turistas anuales con un importe anual de 7.560 .000 pesos chilenos, destinados a su puesta en funcionamiento y conservación. Usualmente son visitantes que vienen desde Santiago. Para inscribirse es necesario realizar una reserva vía telefónica o mail 
a través del sitio web de Ferrocarriles del Estado en su sección de trenes turísticos (http://www.efe.cl) o por la página Aconcagua Travel (http://aconcaguatravel.cl).

El tour se inicia con una visita a la Maestranza de Los Andes para conocer las locomotoras y coches del trasandino. El ingeniero Sergio Carmona, quién dirige la operación, hace una guía in situ de la historia y aspectos técnicos del trasandino. Tras preparar la góndola carril, los turistas suben para comenzar el viaje, siguiendo la orilla izquierda del río Aconcagua bordeando la montaña. Llegando al sector del Salto del Soldado, tras cruzar su primer túnel, se hace una parada en el puente de arco para bajar del vehículo y contemplar el paisaje. El viaje se reanuda, culminando en la Estación de Río Blanco, donde tras un recorrido por la estación, un vehículo conduce a los turistas a almorzar al restaurant El Ventisquero. Terminada la merienda, se descansa en el patio del lugar donde hay un sector de juegos infantiles, animales de corral y miradores. En el retorno a Los Andes se hace una parada a la Estación de Vilcuya para retomar después el viaje a la maestranza (Tour Góndola Carril, 16/08/2015).

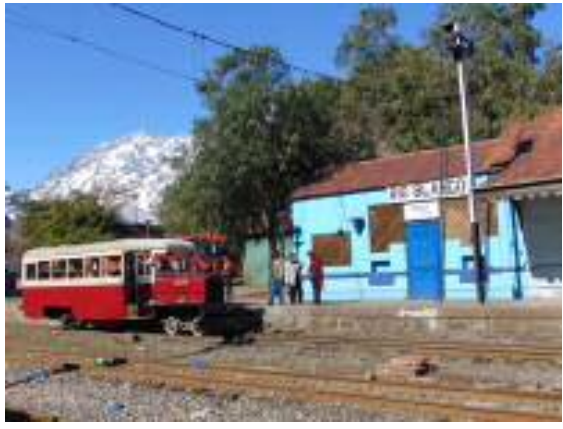

FIG. 3: Góndola Carril en la Estación de Río Blanco

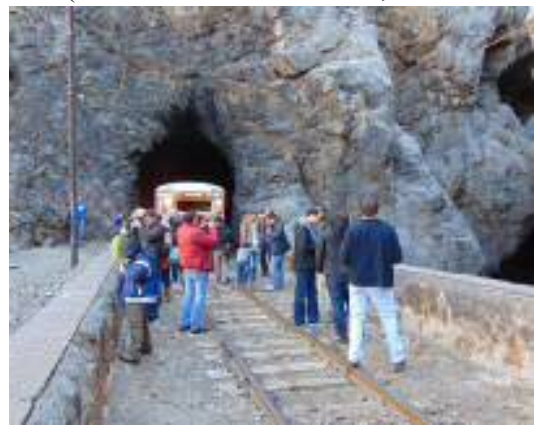

FIG. 4: Turistas en el sector del Salto del Soldado

\section{Maestranza Ferroviaria de Los Andes}

Ubicada en el centro histórico de la ciudad, la Maestranza de Los Andes guarda un importante valor histórico y simbólico para la comunidad y sus ex trabajadores. Posee una imponente infraestructura con galpones, bodegas, subestación eléctrica, tornamesa y las piezas históricas del ferrocarril que constan de la góndola carril T-1024 (1926), locomotora a vapor con cremallera Z-3348 (1908), barrenieves rotatorio a vapor TC-1 (1907) y automotor diésel ADI-1015 (1956), junto a seis piezas más que se encuentra esperando restauración en los galpones de la maestranza. Todas estas máquinas fueron declaradas Monumento Nacional por el CMN (Consejo de Monumentos Nacionales). 
Como se vio, desde aquí sale el tour de la góndola carril y su espacio ocasionalmente se ocupa para actividades conmemorativas. La instalación posee toda la planta e infraestructura turística que ofrece la urbe, pero un gran problema es su accesibilidad, pues ésta, en tanto zona industrial, se encuentra permanentemente cerrada lo cual restringe una iniciativa de desarrollo turístico y/o patrimonial. Posee interesante infografía, pero falta señalética y difusión de su valor histórico, no sólo de sus piezas sino del conjunto de la maestranza.

La maestranza se abre sólo para el toury algún evento excepcional. Para el Día del Patrimonio Cultural en agosto de 2015 se desarrolló una gran actividad cultural donde la comunidad visitó las piezas del ferrocarril. Hubo charlas, poesía, bailes típicos y muestra de objetos ligados al tren donde los grandes protagonistas fueron sus ex trabajadores (Día Patrimonio Cultural en Maestranza de Los Andes, 31/05/2015). Esta iniciativa deja entrever no sólo el valor de su infraestructura sino también del patrimonio inmaterial vinculado al transandino.

Para recuperar este espacio es posible desarrollar un proyecto de gran envergadura que habilite de sus dependencias y compatibilice el uso industrial con el uso turístico. Un gran obstáculo al desarrollo de proyectos es la falta de compromiso por parte de las instituciones y, sobre todo, de fuentes de financiamiento. Sin embargo, Sergio Carmona y su equipo se encuentran trabajando en el automotor diésel y la locomotora a vapor, mientras el coche de pasajeros It-83 de 1905 posee un gran estado de avance en su restauración. Una vez que estén habilitados para el viaje, su puesta en marcha incrementará su atractivo y capacidad de carga para el tour.

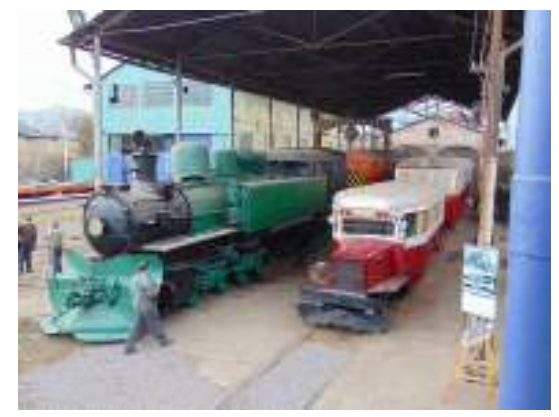

FIG. 5: Piezas históricas del trasandino

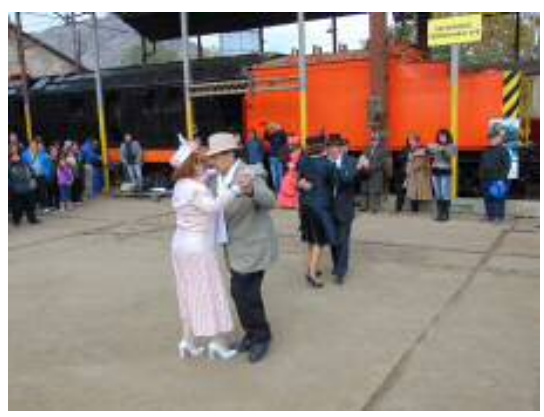

FIG. 6: Celebración del Día del Patrimonio Cultural 2015 


\section{Campamento Ferroviario EI Salto del Soldado}

A 28 kilómetros de Los Andes en el camino internacional, existe una formación geológica conocida como El Salto del Soldado, un interesante acantilado rocoso de más de mil metros de altura que guarda un valor paisajístico e histórico singular. El origen de su nombre se asocia a la independencia chilena. Según cuenta la leyenda, un soldado patriota que escapaba de las tropas hispanas saltó con su caballo el acantilado que separaba el trecho entre ambas superficies rocosas escapando así de sus perseguidores. Junto a la leyenda que le da nombre al sitio, existe una riqueza natural donde río, montaña, vegetación y fauna convergen en un todo armónico.

Pero la historia del lugar también se vincula al tren. Existe aún la opinión entre los lugareños de que una estructura existente en el cajón del río correspondía a un tambo o refugio de la época incaica, sin embargo una investigación arqueológica desmiente esa idea señalando que en realidad fue un campamento de trabajadores ferroviarios de fines del siglo XIX (Stehberg, 1997). En efecto, el Salto del Soldado fue la primera posta ferroviaria del trasandino, donde había una pequeña estación provisional, lugar desde el cual se inició el trabajo de perforación de la montaña y la instalación de puentes y galerías (Moraga, 2013: p. 26). A la fecha, algunas de sus paredes se encuentran colapsadas y con abundante vegetación en su interior, pero salvo estos detalles, se encuentra en buen estado, dibujando una estructura robusta y singular. Así, la zona posee un valor cultural excepcional por la infraestructura (campamento, vía férrea, túnel) y por su relato histórico. Junto al patrimonio cultural, la zona tiene un gran potencial para el turismo de naturaleza, por los senderos y paisajes cordilleranos que posee. Todo el conjunto puede apreciarse desde la berma del camino internacional, una explanada donde es posible detenerse, contemplar y fotografiar el paisaje.

Para acceder a la cuenca del río, hay un sendero sinuoso y hasta peligroso, lo cual lo hace inadecuado para caminar, sino a través de un trekking de mediana dificultad. No obstante, considerando su valor paisajístico es posible integrarla en el contexto de un circuito turístico o apreciar su valor desde un mirador habilitado. Para ello es necesario dotarla de señalética e información gráfica que resalte las cualidades de los recursos patrimoniales. Según la última información sobre construcción de infraestructura para el turismo, el Ministerio de Obras Públicas (MOP) estaría comprometiendo recursos para la región con la elaboración del Plan Regional de Infraestructura MOP de Apoyo al Turismo, lo cual eventualmente pondría en valor los hitos culturales del camino internacional. 


\section{Campamento Ferroviario EI Salto del Soldado}

A 28 kilómetros de Los Andes en el camino internacional, existe una formación geológica conocida como El Salto del Soldado, un interesante acantilado rocoso de más de mil metros de altura que guarda un valor paisajístico e histórico singular. El origen de su nombre se asocia a la independencia chilena. Según cuenta la leyenda, un soldado patriota que escapaba de las tropas hispanas saltó con su caballo el acantilado que separaba el trecho entre ambas superficies rocosas escapando así de sus perseguidores. Junto a la leyenda que le da nombre al sitio, existe una riqueza natural donde río, montaña, vegetación y fauna convergen en un todo armónico.

Pero la historia del lugar también se vincula al tren. Existe aún la opinión entre los lugareños de que una estructura existente en el cajón del río correspondía a un tambo o refugio de la época incaica, sin embargo una investigación arqueológica desmiente esa idea señalando que en realidad fue un campamento de trabajadores ferroviarios de fines del siglo XIX (Stehberg, 1997). En efecto, el Salto del Soldado fue la primera posta ferroviaria del trasandino, donde había una pequeña estación provisional, lugar desde el cual se inició el trabajo de perforación de la montaña y la instalación de puentes y galerías (Moraga, 2013: p. 26). A la fecha, algunas de sus paredes se encuentran colapsadas y con abundante vegetación en su interior, pero salvo estos detalles, se encuentra en buen estado, dibujando una estructura robusta y singular. Así, la zona posee un valor cultural excepcional por la infraestructura (campamento, vía férrea, túnel) y por su relato histórico. Junto al patrimonio cultural, la zona tiene un gran potencial para el turismo de naturaleza, por los senderos y paisajes cordilleranos que posee. Todo el conjunto puede apreciarse desde la berma del camino internacional, una explanada donde es posible detenerse, contemplar y fotografiar el paisaje.

Para acceder a la cuenca del río, hay un sendero sinuoso y hasta peligroso, lo cual lo hace inadecuado para caminar, sino a través de un trekking de mediana dificultad. No obstante, considerando su valor paisajístico es posible integrarla en el contexto de un circuito turístico o apreciar su valor desde un mirador habilitado. Para ello es necesario dotarla de señalética e información gráfica que resalte las cualidades de los recursos patrimoniales. Según la última información sobre construcción de infraestructura para el turismo, el Ministerio de Obras Públicas (MOP) estaría comprometiendo recursos para la región con la elaboración del Plan Regional de Infraestructura MOP de Apoyo al Turismo, lo cual eventualmente pondría en valor los hitos culturales del camino internacional. 


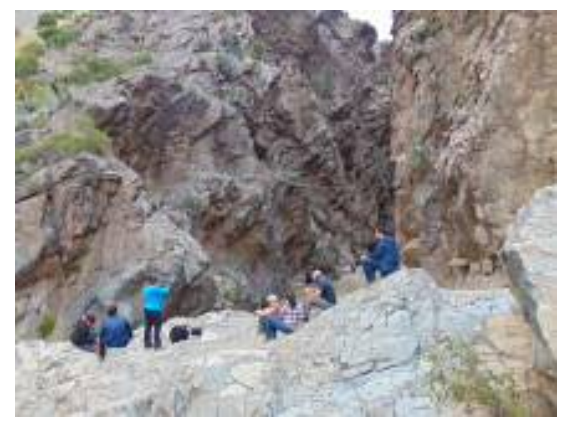

FIG. 7: Visitantes en la boca del Salto del Soldado

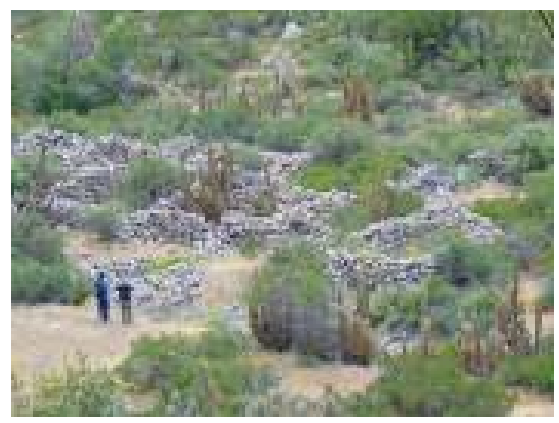

FIG.8: Restos del campamento de trabajadores del ferrocarril

\section{Estación de Ferrocarriles de Río Blanco}

Hacia 1904 la Estación de Ferrocarriles de Río Blanco "sirvió en sus inicios como estación terminal, conforme avanzaban los trabajos, donde los pasajeros debían transbordar en carruajes para seguir rumbo a Argentina" (Moraga, 2013: p. 126), entrando en operación en 1906, momento de su inauguración. La Estación fue declarada Monumento Nacional en el 2007 por su valor histórico, pues fue una de las principales estaciones del trasandino. Desde Río Blanco se preparaban los trenes para enfrentar las fuertes pendientes auxiliados por el sistema de cremalleras, además "servía de centro de operaciones de los despejes de la vía en invierno y centro de acopio de vagones". Junto al edificio de la estación, el conjunto ferroviario comprende una oficina de correos, un policlínico, habitaciones para los trabajadores, casas de funcionarios, un retén de carabineros, una tornamesa, estanque de agua, casa de máquinas, oficinas y red de agua potable (CMN, 2007).

La Estación de Río Blanco es el punto de llegada de la góndola carril, instaurándose como un hito del tour. Pese a este uso, la estación puede potenciarse como un recurso independiente de este viaje, habilitando sus dependencias creando un museo o sitio de interpretación. Sin embargo, su relativa distancia de Los Andes exige la instalación de un equipamiento turístico mínimo para el desarrollo de excursiones a pie, dotarla de señalética y vías de acceso, así también como mejorar la gestión de residuos. Actualmente funciona como punto de llegada y salida de trenes de transporte del mineral de Minera Andina de Codelco hacia el puerto de Ventanas, factor a considerar en una intervención. Necesario es mencionar que el sector de Río Blanco junto a su poblado posee una gran cantidad de recursos naturales y culturales para un desarrollo turístico integral. En el poblado encontramos diversos recursos patrimoniales con un alto grado de desaprovechamiento: el Museo de 
Alta Montaña, la Piscicultura, la Reserva Nacional de Río Blanco, que junto a la Estación de ferrocarriles es un conjunto que puede ser potenciado creando rutas patrimoniales.

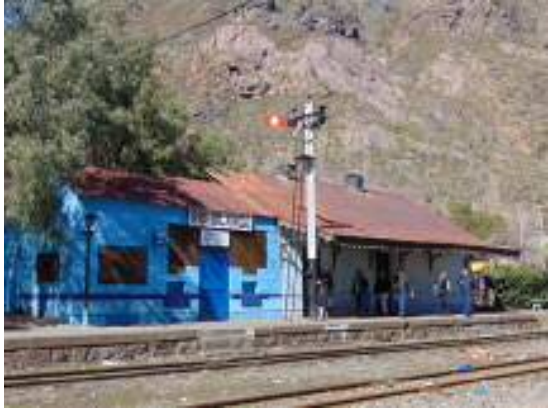

FIG. 9: Estación de Río Blanco

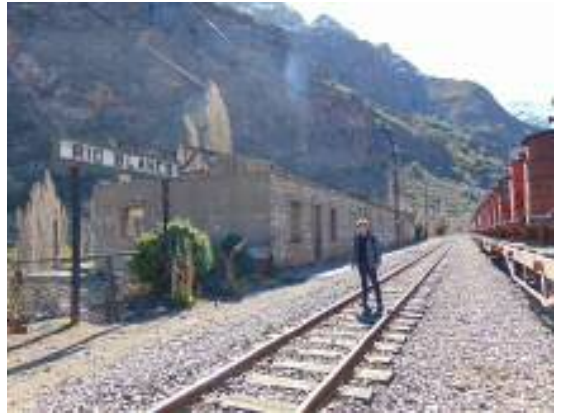

Fig. 10: Línea y edificaciones en la Estación de Río Blanco

\section{Estación de Ferrocarriles Hermanos Clark}

La Estación Hermanos Clark (anteriormente llamada Estación Juncal) es la única estación al oriente de Río Blanco en la cordillera que conserva su infraestructura (de las estaciones de Guardia Vieja, Caracoles y Portillo no quedan vestigios). Según Moraga (2013) "Este lugar había sido escogido por los ingenieros para construir la estación, y planificar toda la infraestructura necesaria para la construcción y operación de este ferrocarril". En la estación se instaló una tornamesa para invertir las locomotoras y el barrenieves, un galpón para guardarlas, carbonera, desvíos, un pozo de agua y la estación propiamente tal, construida con revestimiento en piedra con un corredor en su frontis (p. 127). Más tarde con el proceso de electrificación del trasandino se instala una subestación eléctrica.

Con el cese de operaciones del trasandino las instalaciones sufrieron un progresivo deterioro por el robo y venta de material, así como por el uso de sus instalaciones como campo de tiro por el ejército. A pesar de estas vicisitudes, la estación conserva su infraestructura base que se empina de forma majestuosa en la cordillera. A su alrededor se dejan ver los puentes, túneles y galerías, que testimonían las dificultades de construcción en altura. En el 2000 se presenta un informe al CMN para declarar a la Estación Hermanos Clark con la categoria de Monumento Nacional, pero su postulación fue rechazada (Carmona, 2007: p. 15).

La zona de Juncal guarda un valor paisajistico excepcional. Parte de la línea ferrea pasa por el Parque Juncal Andino, un proyecto privado de conservación de la biodiversidad, 
protegida en el marco de la Convención de RAMSAR donde se realiza una pequeña actividad turística para montañistas y científicos (https://parqueandinojuncal.cl). Destacan sus bellos humedales, la fauna y flora nativa y el imponente glacial Juncal.

La Estación Hermanos Clark se encuentra a varios kilometros de la ciudad, carece completamente de planta turística y su accesibilidad es dificultosa por la existencia del río Juncal, no logrando llegar allí sino por medio de una sinuosa caminata entre cuestas, cruzando el río por los maltrechos puentes del tren. A pesar de ello, por su valor histórico, el paisaje de montaña y la singularidad de su emplazamiento, la convierten en una extraordinaria muestra de la ingenieria ferroviaria. Por su actual abandono es necesario solicitar medidas de protección para evitar su pérdida. A mediano plazo, un mirador dotado de información histórica sería ideal para contemplar el paisaje ferroviario y poner en valor sus maltrechas instalaciones.

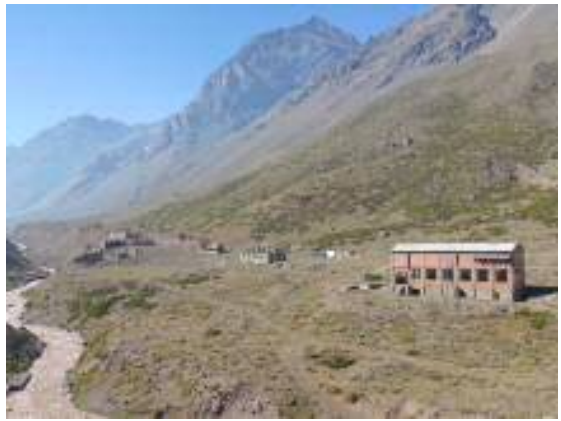

FIG. 11: Panorámica de la Estación Hermanos Clark

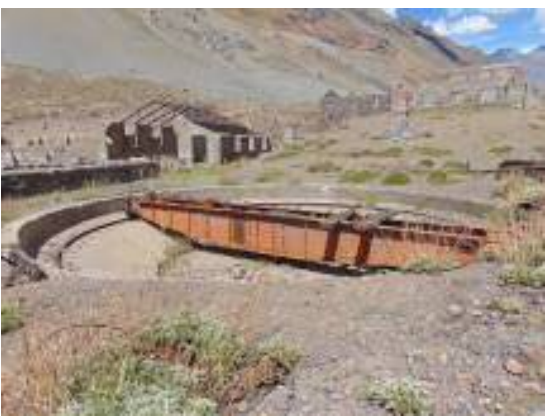

FIG. 12: De abajo hacia arriba: tornamesa, casa de máquinas, monolito y estación de Juncal

\section{POTENCIALIDAD TURÍSTICA DEL PATRIMONIO FERROVIARIO}

La Tabla No 2 correspondiente a un Diagnóstico FODA fue construída en base a informes, diagnósticos, entrevistas, prospecciones territoriales, planificaciones urbanas, entre otras fuentes de información, y sistematiza la situación actual del patrimonio ferroviario de Los Andes considerando su potencial turístico. En base a la clasificación de los recursos territoriales turísticos de Camara y Morcate (2014), tendremos un panorama integral del patrimonio cultural material e inmaterial del Ferrocarril Trasandino Chileno, examinando su potencial turístico y probable desarrollo de productos de acuerdo a los contextos territoriales e institucionales de Los Andes. 


\section{Tabla No 3: Diagnóstico FODA en torno a la Potencialidad Turística del Ferrocarril Trasandino Chileno}

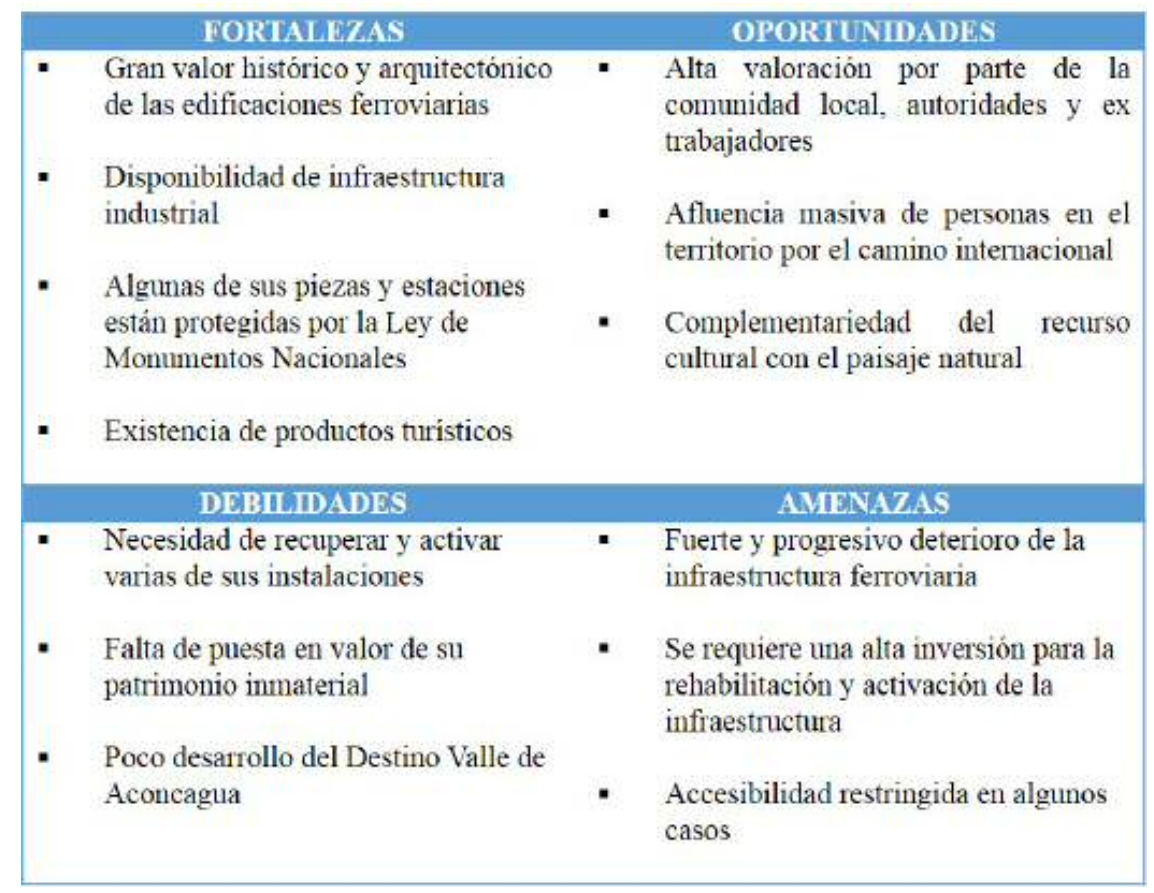

Fuente: Elaboración propia.

\section{a. Fortalezas}

La infraestructura asociada al Ferrocarril Trasandino corresponde a bienes históricosmonumentales con una alta significación patrimonial. Cada sitio por sí solo posee singularidades históricas y arquitectónicas que hacen única cada una de sus instalaciones. Junto a las estructuras ferroviarias, se identifica el paisaje cordillerano como un valor asociado que contextualiza y explica las características de un ferrocarril adaptado a la montaña. Gran parte de su insfraestructura se ha perdido o deteriorado, pero quedan aún importantes remanentes materiales entre Los Andes y la zona de Juncal. Estos recursos constan desde locomotoras hasta estaciones ferroviarias en estado variable de conservación y uso, que guardan un gran potencial para la puesta en valor para el turismo y el patrimonio. 
El valor del Ferrocarril Trasandino Chileno se encuentra oficializado por el CMN con la declaración de Monumento Nacional a diez piezas históricas del ferrocarril junto a la Estación de Río Blanco. La ex Estación de Ferrocarriles de Los Andes tiene una alta valoración por parte de la comunidad y se proyecta la rehabilitación del resto de sus dependencias. Por su lado, aún cuando se rechazó la postulación de Monumento Nacional para la Estación Hermanos Clark, es necesario insistir en su repostulación o ponerla en valor de otras formas por su alto significado histórico.

Se ha desarrollado un producto turístico con la creación del Tour de la Góndola Carril que ha puesto en valor sus instalaciones hasta el sector de Río Blanco, volviendo a resucitar así la antigua gloria del trasandino. Asimismo, la ex Estación de Ferrocarriles de Los Andes se ha habilitado para diversas actividades, pero puede fortalecerse todavía más. Otros puntos como la Maestranza de Ferrocarriles de Los Andes, el campamento ferroviario de El Salto del Soldado, la Estación de Río Blanco y la Estación Hermanos Clark, aunque parcial o completamente abandonados, poseen cualidades históricas, materiales y paisajísticas para distintos grados intervención turística y/o patrimonial.

\section{b. Oportunidades}

El Ferrocarril Trasandino tiene una amplia valoración por parte de la comunidad y las autoridades andinas, pues forma parte de la historia y la memoria local. Los procesos de patrimonialización del ferrocarril han sido protagonizados por personas vinculadas al tren, ex ferroviarios y dirigentes locales, que unidos a la comunidad han recuperado parte importante de su infraestructura, junto a la colaboración de importantes instituciones locales como Codelco División Andina, la Corporación de Desarrollo ProAconcagua y la Municipalidad de Los Andes. Dichas experiencias convierten en una posibilidad real nuevas acciones de conservación y rehabilitación del patrimonio ferroviario del trasandino.

Una ventaja que tiene este patrimonio es que está distribuido junto al camino internacional, desde Los Andes hasta la aduana, en un trayecto donde circula una gran cantidad de personas. La evolución de visitantes y pernoctaciones en las provincias de Los Andes y San Felipe se ha incrementado de forma substantiva entre 2004 y 2012 tanto de nacionales como extranjeros (Aconcagua 2020, Pág. 11). Así, considerando el flujo y perfil de personas que podrían conocer el patrimonio ferroviario tenemos: 1) residentes en Los Andes y el Valle de Aconcagua; 2) residentes Región Metropolitana y V-Región Costa; 3) turistas argentinos-brasileños; y 4) ferroaficionados.

Junto a la infraestructra ferroviaria, existe un recurso paisajístico que complementa y explica las particularidades del trasandino, un tren acondicionado para el clima de montaña. El imponente paisaje montañés por sí solo posee una belleza y 
biodiversidad riquísima que complementa a los bienes culturales. La existencia de la Reserva Nacional de Río Blanco y el Parque Andino Juncal, posicionan y legitiman el valor natural del espacio cordillerano de los Andes por donde cruzó el ferrocarril.

\section{c. Debilidades}

Pese a que se ha trabajado por recuperar este patrimonio ferroviario, existe una abundante infraestructura aún abandonaba y no puesta en valor, que contempla estaciones, maestranza, monumentos, piezas ferroviarias, subestaciones eléctricas, habitaciones de trabajadores, túneles, galerías, paredes de contención, desagues, postes eléctricos, entre otros, con un gran valor histórico-cultural. No obstante lo anterior, EFE ha proseguido con una política de venta de su infraestructura, licitaciones muchas veces ganadas por contratistas que carecen de un sentido de protección patrimonial, arrasando con todo el material comercializable.

En cuanto a su patrimonio cultural inmaterial, existe un grupo de ex trabajadores del ferrocarril que se reúnen en la Unión de Obreros Ferroviarios de Los Andes, institución que presta servicios mutuales y recreativos a sus socios; mientras en la ciudad, perviven poblaciones de obreros, testigos de la historia social del tren. Importante es destacar las actividades el Día del Patrimonio Cultural (último domingo del mes de mayo) y el Día Nacional del Trabajador Ferroviario (6 de octubre), que se celebran a nivel local y potencian la identidad ferroviaria de Los Andes.

Peseahaberunimportantebagajederecursospatrimoniales, eldestinoValledeAconcaguaesun espacio emergente en términos turísticos, encontrándose completamente desaprovechados sus recursos culturales y naturales por la ausencia de una oferta e infraestructura turística, así como de la inexistencia de una gobernaza para la articulación de acciones conjuntas entre el sector público y privado, que promuevan el desarrollo integral del turismo en el territorio.

\section{d. Amenazas}

Desde el cese de operaciones el Ferrocarril Trasandino Chileno comenzó un lento pero sostenido proceso de deterioro de su infraestructura, especialmente desde Río Blanco hacia la cordillera. Posteriormente, la pérdida de material rodante, edificaciones y materialidad de la vía fue acentuada por el remate que hizo EFE del acero de las vías no operativas. De este modo, la venta, destrucción, deterioro, falta de mantenimiento, robo y uso de instalaciones para ejercicios militares, han contribuido a dañar y destruir la infraestructura del transadino.

La salvaguarda de la materialidad requiere una gran inversión, tanto para la recuperación de material rodante, edificaciones y estaciones. Ciertamente existen precedentes en la rehabilitación de edificios, como la ex estación de Los Andes y las piezas del trasandino, 
pero estas requieren inversiones millonarias que se concretran tras una exhaustiva gestión e implementación. Existe toda una superestructura turística, patrimonial, institucional y empresarial a nivel nacional (ACCPF, CMN, EFE, SERNATUR, MOP), regional (GORE, Consejo de la Cultura y Las Artes, universidades) y local (Minera Andina, Municipalidad de Los Andes, Corporación de Desarrollo Proaconcagua), que asociadas o individualmente pueden contribuir al financiamiento de algún tipo de proyecto.

La accesibilidad se encuentra restringida por la presencia de los ríos Aconcagua y Juncal, los desniveles de montaña y la propiedad privada en algunos de sus tramos, lo que impide su ingreso. Es, por ejemplo, el caso del campamento ferroviario del Salto del Soldado, donde existe una sendero con peligrosos desniveles, o bien la Estación Hermanos Clark, cuyo acceso está limitado por el río Juncal, siendo posible llegar a sus instalaciones tras una larga caminata al pie de la montaña. El ingreso a La Maestranza de Los Andes se encuentra restringida por su actual uso industrial.

\section{PROPUESTA DE PRODUCTOS TURÍSTICO-PATRIMONIALES}

Considerando las particularidades y el conjunto de los recursos culturales del ex Ferrocarril Trasandino Chileno, podemos sugerir un portafolio de productos turísticos posibles de ser desarrollados.

\section{Creación de la Ruta Patrimonial del Ferrocarril Trasandino}

Una ruta patrimonial puede conectar distintas edificaciones que sirvieron para la operación del tren. En vista a esto es posible desarrollar una o varias rutas turísticas desde Los Andes hasta Juncal que unifiquen en un corredor turístico la historia del Ferrocarril Trasandino Chileno a partir de sus estaciones y sitios. Un itinerario en un bus o un vehículo menor junto a un instruido guía podría constituir un interesante producto turístico. Como antecedente, se han realizado rutas patrimoniales en Los Andes dirigidas a estudiantes, la comunidad y turistas que han llegado a contemplar la ex Estación de Ferrocarriles de Los Andes y su mural el "Abrazo de Los Pueblos", desarrolladas por instituciones como CITYP, ProAconcagua o el Círculo Patrimonial Chileno. Los hitos del ferrocarril constituyen nodos turísticos junto a otros hitos de interés cultural en un espacio acotado. Es el caso de la zona de Juncal, que posee una alta densidad de bienes culturales expresados en el Tambo Ojos de agua, un refugio de correos colonial, el Paso de Caracoles, el Parque Andino Juncal y el complejo ferroviario Hermanos Clark.

\section{Habilitación de miradores, señalética e información}

Considerando el alto flujo de personas por esta zona, se pueden implementar miradores 
con señalética e infografía que relate la historia del tren. El alto valor del paisaje industrialferroviario adosado en un territorio de un paisaje excepcional puede ser usado como recurso escénico. La existencia de puntos en altura en Salto del Soldado y Juncal permite apreciar toda la magnitud de este paisaje. En el primer sector, la explanada al costado del camino es un sitio de parada frecuente por camioneros y viajeros desde donde se puede apreciar el campamento ferroviario, pero es necesario habilitar una infraestructura minima, pavimentar y ripiar caminos para mejorar el acceso, dotar de estacionamientos y señalética para conocimiento del sitio. Lo mismo en Juncal. Ello contribuíría a poner en valor estos sitios y fortalecer la idea de generar un circuito patrimonial.

\section{Restauración y musealización de estaciones del ferrocarril}

La restauración de estaciones y piezas supone la operación más compleja de la turístificación por la fuerte inversión que requiere. Pese a ello existen antecedentes en el trabajo de restauración y conservación de maquinaría ferroviaria del trasandino, proceso que sigue en curso. En cuanto a las estaciones, existen referencias en la recuperación de la ex Estación de Ferrocarriles de Los Andes, que tras una iniciativa ciudadana e institucional fue recuperada convirtiéndose en un centro cultural. Todavía así, una parte importante de su infraestructura histórica se encuentra en riesgo. La Estación Hermanos Clark a se encuentra en abandono y en un deterioro creciente y la Maestranza Ferrroviaria de Los Andes no se encuentra del todo aprovechada. Una interesante propuesta al respecto busca promover el turismo recuperando zonas urbanas degradadas por el abandono del trasandino, con la proyección de crear un centro que albergue maquinaria y documentos históricos, proteja y rehabilite edificaciones de importancia, de lugar a una pequeña estación para viajes turísticos y alberge eventos nacionales e internacionales de grupos ligados el ferrocarril (León, 2004: p. 32). La idea de un museo ferroviario en la maestranza sigue dando vueltas y se idea la habilitación de un coche-museo para instalarlo en el andén de la estación de Los Andes.

\section{Uso de nuevas tecnologías para el registro de infraestructura ferroviaria}

El uso de las nuevas tecnologías se ha convertido en una nueva herramienta de promoción y comercialización turística potente con la creación de páginas web, folletería electrónica y apps para celulares. Últimamente la catalogación y exhibición de los bienes culturales a través de páginas web ha tomado fuerza con la creación de museos digitales, como es por ejemplo el caso del Museo del Ferrocarril de Catalunya (ver: http://museudelferrocarril. org/es/). Como una forma de rescate del patrimonio ferroviario es necesario inventariar y difundir este patrimonio local por medio de plataformas virtuales. Con los nuevos métodos de registro de objetos e infraestructura a través de escaneo $3 \mathrm{D}$, es posible representar desde pequeñas piezashastaedificaciones completas. Elloseconvierteenunapoderosaherramienta 
de catalogación y difusión del patrimonio ferroviario a bajo costo y de alto impacto.

\section{Potenciar la celebración del Día del Trabajador Ferroviario}

A inicios del siglo XX los trabajadores ferroviarios celebraban la Fiesta del Riel, una celebración en homenaje a sus obreros que posteriormente desapareció. Desde el 2012 se instauró por ley el Día del Trabajador Ferroviario el 4 de octubre y desde entonces sus ex trabajadores lo han celebrado periódicamente. En Los Andes, en la Unión de Obreros Ferroviarios, se celebra intramuros entre los ex trabajadores, montepiadas y sus familias. Esta fiesta conmemora la historia de los ferroviarios, su aporte al desarrollo económico nacional y sus luchas sociales. Crear una celebración pública de este acontecimiento aprovechando las edificaciones ferroviarias, contribuiría a reforzar la identidad local, a poner en valor los bienes culturales y a desarrollar la economía local con la atracción de visitantes.

\section{CONCLUSIONES}

Privilegiando una escala de observación reducida este estudio hizo un análisis integral de los bienes patrimoniales ligados al Ferrocarril Trasandino Chileno y de los factores que influyen en su turistificación, permitiendo determinar las posibilidades de uso de su patrimonio cultural. Las evaluaciones sobre potencial turístico basado en jerarquización de recursos, puntuaciones o presencias, si bien sirven de guía para la toma de decisiones turísticas, no expresan todas las posibilidades, relaciones y valoraciones del patrimonio ferroviario. Junto a ello, una investigación cualitativa densa sobre un conjunto de bienes patrimoniales trae nuevas miradas sobre su posible uso turístico y/o patrimonial, tanto del ferrocarril en su conjunto como a partir de cada una de sus unidades.

El uso turístico de los bienes patrimoniales del trasandino tendrá un aspecto positivo al promover su conservación, rehabilitación y difusión de su legado. El turismo trae evidentes beneficios a la comunidad al aumentar la afluencia de público, contribuyendo al desarrollo del sector hotelero, gastronómico y comercial. Del mismo modo, sirve como recurso histórico-cultural que significa y fortalece la identidad local. Por lo anterior, un conocimiento adecuado de los bienes patrimoniales abre toda una serie de posibilidades de desarrollo, especialmente en Los Andes, donde la propia comunidad ha contribuido al rescate del patrimonio ferroviario y donde existen antecedentes de turistificación. En todo caso, cualquier intervención turística debe velar por la sustentabilidad del territorio y el beneficio de las comunidades.

Con la identificación de los recursos patrimoniales del Ferrocarril Trasandino Chileno es posible pensar en el desarrollo de un turismo ferroviario en Los Andes, pero ello requiere, entre otras acciones, un arduo trabajo de rehabilitación de estaciones y la creación de un 
gran museo que albergue la historia y el patrimonio del trasandino. Las Oficinas Salitreras de Humberstone y Santa Laura, junto a la Ciudad Minera de Sewell, sitios de patrimonio industrial en Chile, fueron declaradas Patrimonio de la Humanidad por la UNESCO, tras cuyo reconocimiento han obtenido financiamiento y han implementado pujantes productos turísticos que han contribuido a la conservación y relevamiento de sus instalaciones. ¿Puede el Ferrocarril Trasandino Chileno obtener la categoría de patrimonio mundial? En base a la investigación realizada el antiguo ferrocarril trasandino posee todas las cualidades para cumplir con los requerimientos para su postulación a Patrimonio de la Humanidad.

\section{BIBLIOGRAFÍA}

Almeida, M. (2009). "Matriz de Avaiação do Potencial Turístico de Localidades Receptoras", Turismo em Análise, V. 20, No 3.

Aconcagua Turismo 2020 (2014). Plan estratégico de ordenación y promoción del turismo en el valle de Aconcagua. Resumen Ejecutivo.

Alliende, M. (1993). Historia del ferrocarril en Chile, Goethe Institut, Pehuén.

Boullon, R. (2006). Planificación del espacio turístico, Editorial Trillas, México.

Casals, M. y Errázuriz, M. (coord.) (2013), Plan Maestro Turístico. Ramal Talca Constitución, Ediciones Universidad Central de Chile, Santiago de Chile.

Camara, C. y Morcate, F. (2014). "Metodología para la identificación, clasificación y evaluación de los recursos territoriales turísticos del centro de ciudad de Fort-deFrance". Arquitectura y Urbanismo, 35.

Carmona, S. (2007). "Electrificación del Ferrocarril Trasandino". El Ferrocarril Trasandino por Juncal Los Andes - Mendoza Argentina, Centro de la Conservación de la Cultura y el Patrimonio de Los Andes, No 1.

CMN (2005). Decreto Exento No 878, "Declaratoria de Monumento Histórico nueve piezas rodantes ferroviarias, correspondientes al ferrocarril trasandino, que se encuentran en la casa de máquinas de Los Andes". Ministerio de Educación, Gobierno de Chile, 30 de junio de 2005.

CMN (2007). Decreto Exento No 1120, "Declaratoria Monumento Nacional en la categoría de Monumento Histórico la Estación de Río Blanco del Ferrocarril Trasandino y Bienes que indica, ubicados en la villa Río Blanco". Ministerio de Educación, Gobierno de Chile, 7 de junio de 2007.

Lacoste, P. (2013). El Ferrocarril Trasandino y el desarrollo de los Andes Centrales argentino-chileno, 1872-2013. Editorial IDEA, Santiago de Chile.

León, M. (2004). Museo Estación del Ferrocarril Trasandino. Memoria de proyecto de Título, Universidad de Chile, Facultad de Arquitectura y Urbanismo, Escuela de Arquitectura.

Moraga, P. (2013). Estaciones Ferroviarias de Chile. Imágenes y Recuerdos.

Santiago, Editorial Ricaaventura E.I.R.I. 
Moraga, P. (2015a). El Ferrocarril Trasandino. La conquista de la Cordillera de Los Andes. Editorial Ricaaventura EIRL, Santiago de Chile.

Moraga, P. (2015b). El imaginario del ferrocarril en Chile: 1860-1960. Editorial Ricaaventura E.I.R.L, Santiago de Chile.

Negrete, J. (1987). "La percepción de los recursos turístico de la Provincia de Los Andes". Revista de Geografía de Valparaíso, No 18.

OEA (1978). Metodología de Inventario turístico en Quito. Curso Interamericano de Planificación del Desarrollo Turístico. México D.F. Organización de Estados Americanos.

OMT (1978). Evaluación de los recursos turísticos. Madrid, Organización Mundial de Turismo.

Rojas, L. y Romero, M. (Editores) (2006). Engranajes de la memoria. Puesta en valor del patrimonio de la Maestranza Central de San Bernardo. Comité Defensa Patrimonio Maestranza San Bernardo / Colectivo Rescata.

Rojas, L., Carvajal, M., y Ortega, A. (2015). Entre rieles y chimeneas. Un recorrido por el barrio obrero y ferroviario San Eugenio, FONDART Regional.

SECTUR (2005). Identificación de potencialidades turísticas en regiones y municipios. México D.F, Fascículo 8.

Seisdedos, S. (2009). "El Ferrocarril trasandino". ARQ (Santiago), (71).

Stehberg, R. (1997). "Investigaciones de la red vial Inkaica en el sector de salto El Soldado (valle de Aconcagua, Chile Central), Actas del XII Congreso Nacional de Arqueología Argentina, La Plata, Argentina, 22-26 de septiembre de 1997, Tomo I.

Thomson, I. y Argerstein, D. (2000). Historia del Ferrocarril en Chile. DIBAM, Santiago de Chile.

Thomson, I. (2003). El autofinanciamiento del patrimonio: dos estudios. Cuadernos del Consejo de Monumentos Nacionales.

Thomson, I. (2005). "El Ferrocarril Trasandino: un desastre financiero de cien años que todavía atrae a los inversores". Estudios Internacionales, Año 38, No. 148.

Thomson, I. (2007). Los trenes turísticos de América del Sur. http://www. institutoferroviario.cl/2015/05/los-trenes-turisticos-de-amercia-del-sursus-raices-ycrecimiento-las-caracteristicas-del-mercado-y-las-posibilidades-de-financiamiento-defuentes-externas/

\section{PÁGINAS WEB}

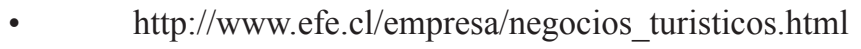

- $\quad h t t p: / / a c o n c a g u a t r a v e l . c l$

- http://www.monumentos.cl/consejo/606/w3-channel.html

- https://parqueandinojuncal.cl

- $\quad$ http://museudelferrocarril.org/es/ 